\title{
Study the Rate Constant of Photostabilization of PVC in Presence of Schiff's Bases of Sulphamethoxazole
}

\author{
Zainab Hussain*, Emad Yousif**, Ali Altaie* and Dheaa Zageer** \\ *Department of Chemistry, College of Science for Woman, Baghdad University, Baghdad-Iraq. \\ ${ }^{* * *}$ Department of Chemistry, College of Science, Al-Nahrain University, Baghdad-Iraq.
}

\begin{abstract}
The photostabilization of poly (vinyl chloride) (PVC) films by Sulphamethoxazole Schiff's bases compounds was investigated. The PVC films containing concentration of compounds $\cdot, 0 \%$ by weight were produced by casting method from tetrahydrofuran (THF) solvent. The photostabilization activities of these compounds were determined by calculating the photodegradation rate constant for photostabilizer $\left(\mathrm{k}_{\mathrm{d}}\right)$. The stabilizing efficiency of sulphamethoxazole-Schiff's base derivatives is attributed to the replacement of the labile chlorine atoms on the PVC chains by a relatively more stable moiety of the organic stabilizer.
\end{abstract}

Keywords: Schiff's bases, Poly(vinyl chloride), Sulphamethoxazole.

\section{Introduction}

Poly (vinyl chloride), better known by its abbreviation PVC, is one of the most versatile plastics. It is the second largest manufactured resin by volume worldwide [1]; However, PVC suffers from poor thermal and light stability. It undergoes rapid autocatalytic dehydrochlorination upon exposure to heat and light $[r, r]$ during its molding and use, respectively. As a result, conjugated polyene sequences are formed from the beginning of the reaction, and they give rise to discoloration of the polymer and seriously change its physical properties [₹]. The low cost and the good performance of poly (vinyl chloride) products have increased the utilization of this polymer in building, mainly in exterior application, such as window profiles, cladding structure, and siding [ ${ }^{\circ}$ ]; However, ultimate user acceptance of the PVC products for outdoor building applications will depend on their ability to resist photodegradation over long periods of sunlight exposure. To ensure weatherability, the PVC resin needs to be compounded and processed properly using suitable additives, leading to a complex material whose behavior and properties are quite different from the PVC resin by itself [ๆ]. Recently, scientists have used Schiff's bases compounds as Photostabilizers of poly (vinyl chloride) polymer against photodegradation by ultraviolate radiation $\left[\mathrm{V}_{-}{ }^{9}\right]$. As part of our on-going research in the photostabilization of poly (vinyl chloride), the photostabilization of PVC was studied using five Schiff's bases derivatives of sulphamethoxazole have been prepared in alcoholic medium.

\section{Experimental Materials}

The following Schiff's bases compounds were all prepared by the method described by Hussain et al. [ $[\cdot]$ :

( $)$ \&-[( -hydroxy-benzylidene $)$-amino $]-N-\left({ }^{0}\right.$ methyl-isoxazol-r-yl)-benzene ulfonamide.

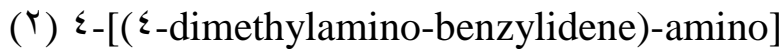
$-N$-( ${ }^{0}$-methyl-isoxazol-r-yl)- benzene sulfonamide.

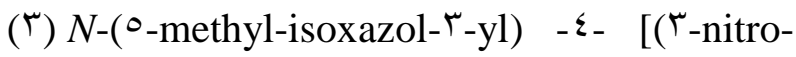
benzylidene) -amino] -benzene sulfonamide.

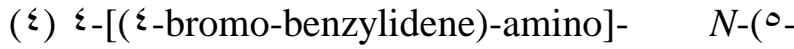
methyl-isoxazol- $r$-yl)- benzene sulfonamide.

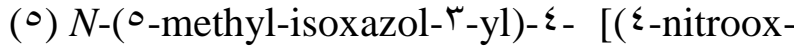
benzylidene)-amino]-benzene sulfonamide. 


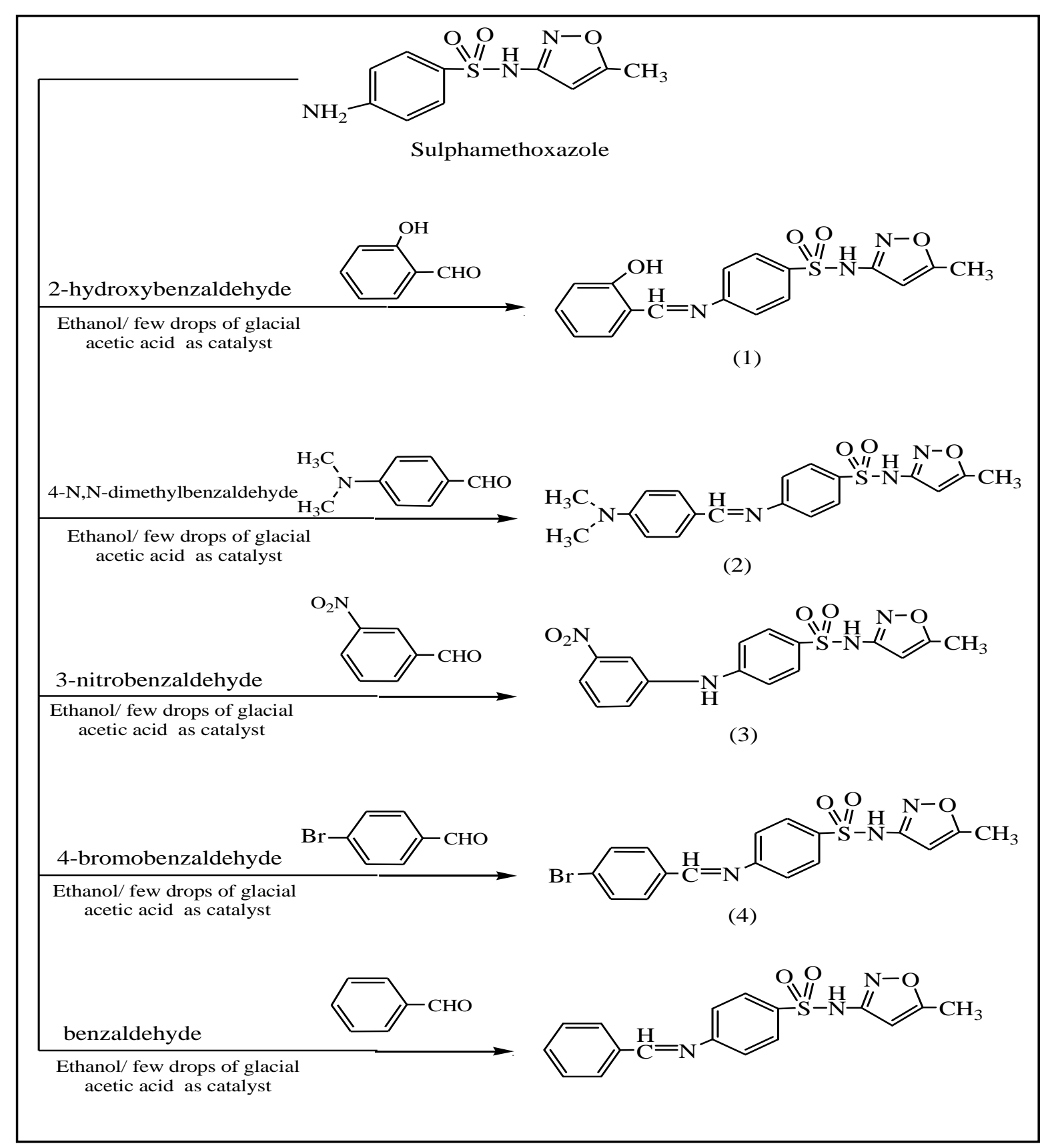

Scheme (') Scheme of preparation of Schiff's bases from sulphamethoxazole.

\section{Experimental Techniques} Films preparation

Commercial poly(vinyl chloride) supplied by Petkim company (Turkey) was reprecipitated from THF solution by alcohol several times and finally dried under vacuum at room temperature for $r \leqslant$ hours. Fixed concentrations of poly(vinyl chloride) solution $\left({ }^{\circ} \mathrm{g} / \cdots \mathrm{ml}\right)$ in tetrahydrofuran were used to prepare polymer films with $r \cdot \mu \mathrm{m}$ thickness (measured by a micrometer type $r 7) \cdot A$, Germany). The prepared compounds $(\cdot, 0 \%$ concentrations) were added to the films. The films were prepared by evaporation technique at room temperature for $r \leqslant$ hours, to remove the possible residual tetrahydrofuran solvent.

\section{Irradiation Experiments}

\section{Accelerated testing technique}

UV light was used for irradiation of polymer films. The lamp giving spectrum

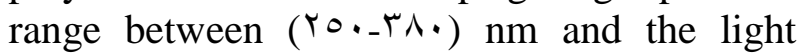
intensity is $\tau, r \times 1 \cdot \cdot^{-9}$ ein $\mathrm{dm}^{-r} \mathrm{sec}^{-1}$. The polymer films samples were fixed vertically and parallel to the lamps to be sure that UV incident radiation is vertically incident on the 
Journal of Al-Nahrain University Science

samples, the irradiation samples are changed places from time to time to be sure that the intensity of light incident on all samples is equal. The distance between the polymer films and light source was $1 \cdot \mathrm{cm}$.

\section{rr. Photodegradation measuring method} Measuring the photodegradation rate of Poly (vinyl chloride) films using ultraviolet visible spectrophotometer

The ultraviolet-visible spectrophotometer type Shimadzu UV-VIS. 17. was used to measure the changes in the UV-visible spectrum during the irradiation time for each compound at the maximum absorption band $\left(\lambda_{\max }\right)$. The absorption spectrum was measured in the range of $\left(r_{\cdots} \varepsilon \cdots\right) \mathrm{nm}$ and the $\left(\lambda_{\max }\right)$ at each absorption was also recorded for different irradiation times. The infinite irradiation time was considered and the infinite absorption $\left(\mathrm{A}_{\infty}\right)$ was assumed to be after the infinite irradiation time. To determine the photodegradation rate constant for photostabilizer $\left(\mathrm{k}_{\mathrm{d}}\right)$, the first order equation was used:

$$
\ln (\mathrm{a}-\mathrm{x})=\ln \mathrm{a}-\mathrm{k}_{\mathrm{d}} \mathrm{t}
$$

where a, represent the stabilizer concentration before irradiation, $\mathrm{x}$ represents the change in stabilizer concentration after irradiation time $(\mathrm{t})$.

If $A_{o}$ represents the absorption intensity of the polymer film containing stabilizer before irradiation, $A_{t}$ represents the absorption intensity after $(t)$ time of irradiation, then:

$$
\begin{aligned}
& a=A_{o}-A_{\infty} \\
& x=A_{o}-A_{t} \\
& a-x=A_{o}-A_{\infty}-A_{o}+A_{t}=A_{t}-A_{\infty}
\end{aligned}
$$

substitution of $\mathrm{a}$ and $\mathrm{a}-\mathrm{x}$ from equation $(r)$ in $(1)$ gives:

$$
\ln \left(\mathrm{A}_{\mathrm{t}}-\mathrm{A}_{\infty}\right)=\ln \left(\mathrm{A}_{\mathrm{o}}-\mathrm{A}_{\infty}\right)-\mathrm{k}_{\mathrm{d}} \mathrm{t}
$$

Thus a plot of $\ln \left(A_{t}-A_{\infty}\right)$ versus irradiation time $(t)$ gives straight line with a slope equal $\left(\mathrm{k}_{\mathrm{d}}\right)$ which indicates that photodecomposition of the additives is first order [ 11$]$.

\section{Results and Discussion}

Study of the efficiency of prepared Schiff's basses as photostabilizers of Poly (vinyl chloride) films by ultraviolet spectroscopy
Ultraviolet radiations are known to have deleterious effects on most industrial polymers inducing chemical modification and scission of polymer chain, which ultimately lead to an undesirable loss of the mechanical and surface properties of the irradiated material $[\mathrm{I}]$. Poly (vinyl chloride) suffers from poor thermal and light stability. The prepared Schiff's bases were used as photostabilizers to Poly (vinyl chloride) films comparing with Poly (vinyl chloride) films (blank). The physical properties of additives and polymers play a very important role in determining the additive efficiency in photostabilization or photodegradation of polymers [1\%]. The additives used in this study were chosen to be completely soluble in polymer solvent, THF. It has been noticed that the additives used in the present work are photodecomposed during the photolysis. Thus the photodecomposition rate constant $\left(\mathrm{k}_{\mathrm{d}}\right)$ was calculated (see paragraph $(r))$. The $\left(k_{d}\right)$ values were computed using the UV spectra changes of PVC films thickness ( $\Gamma \cdot \mu \mathrm{m}$ ) containing, $0 \%$ of additives. The plot of irradiation time versus $\ln \left(\mathrm{A}_{\mathrm{t}}-\mathrm{A} \infty\right)$, gives straight line which indicates primarily the first order reaction. The slope equal to the decomposition rate constant $\mathrm{k}_{\mathrm{d}}$. Fig. (1) shows the variation of $\ln \left(A_{t}-A \infty\right)$ with irradiation time for all additives in Poly (vinyl chloride) films at the wavelength $470 \mathrm{~nm}$.

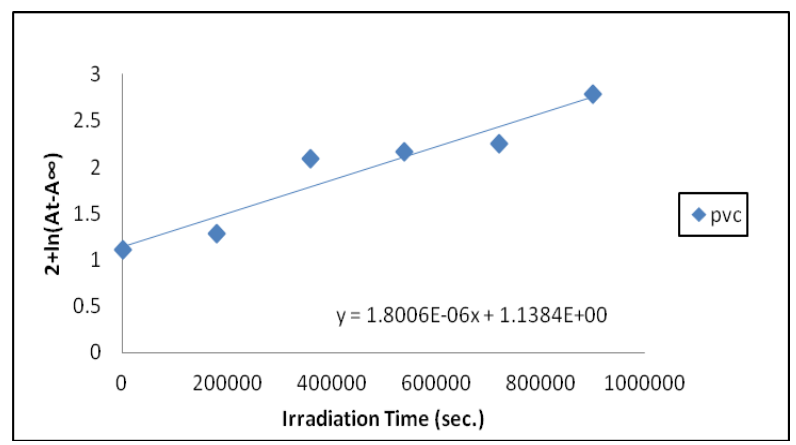

(a)

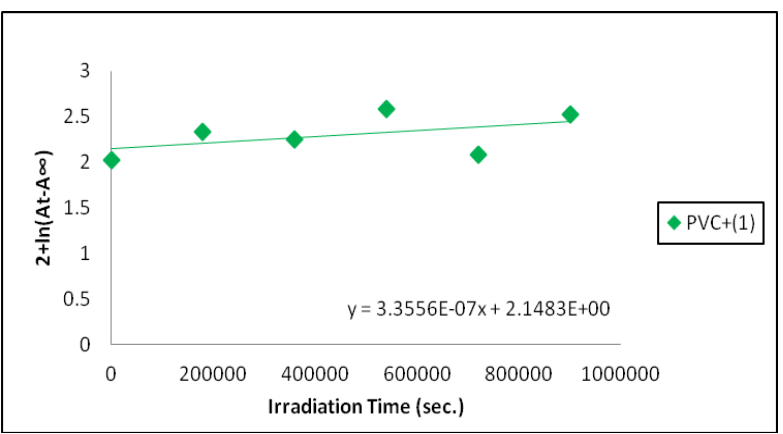


(b)

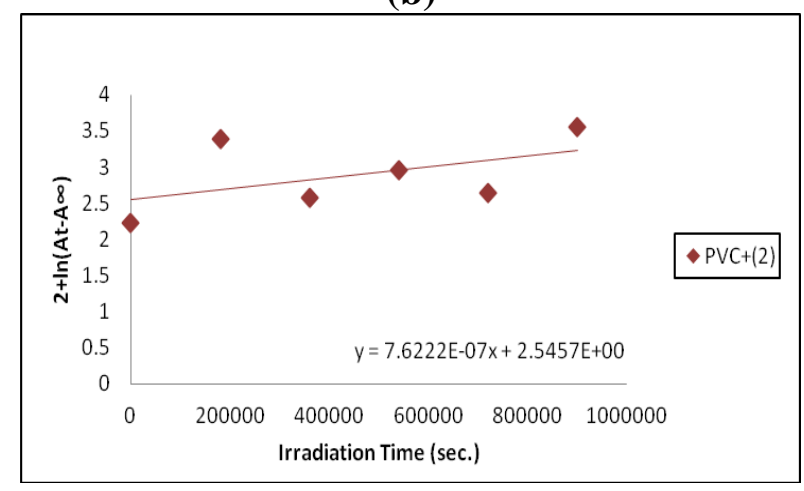

(c)

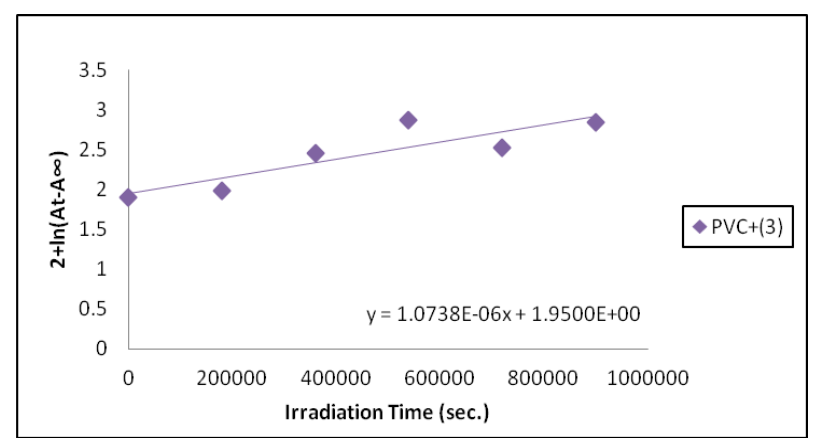

(d)

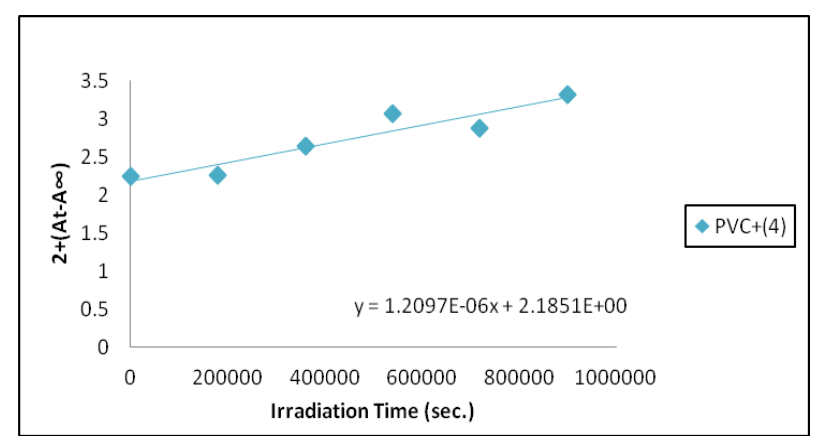

(e)

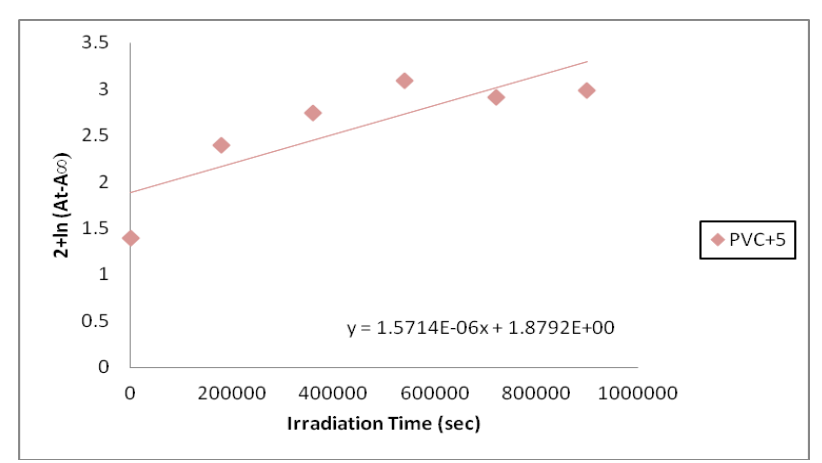

(f)

Fig. (1) Variation of natural logarithm of ln $\left(A_{t}-A_{\infty}\right)$ with irradiation time for prepared Schiff's bases in PVC films.

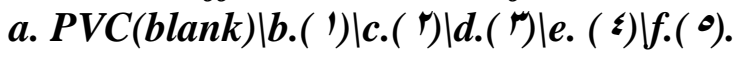

The values of the first order rate constant of all the additives decay in PVC films $\left(\mathrm{k}_{\mathrm{d}}\right)$ calculated by the same way and shown in Table ( 1 ).

Table (')

Photodecomposition rate constant $\left(k_{d}\right)$ of PVC films ( $\left.\boldsymbol{H}_{+} \boldsymbol{\mu m}\right)$ thickness containing -, $0 \%$ of additives.

\begin{tabular}{|c|c|}
\hline Compounds & $k_{d}\left(\sec ^{-1}\right)$ \\
\hline $\mathrm{PVC}+(1)$ & $r, r 007 \times 1 \cdot{ }^{-v}$ \\
\hline $\mathrm{PVC}+(r)$ & V,TYYYXI. -V \\
\hline $\mathrm{PVC}+(\Gamma)$ & $1, \cdot V \Gamma \wedge \times 1 \cdot{ }^{-7}$ \\
\hline $\mathrm{PVC}+(\varepsilon)$ & $1, r .9 \vee \times 1 .-7$ \\
\hline$\overline{\mathrm{PVC}+(0)}$ & $1,0 \vee \backslash \leqslant x) \cdot-1$ \\
\hline PVC(blank) & $1,1 \ldots 7 \times 10^{-7}$ \\
\hline
\end{tabular}

The photostabilizers always posses low $\mathrm{k}_{\mathrm{d}}$ values, which mean that these modified polymers are stable towards UV light. One could notice that $\mathrm{k}_{\mathrm{d}}$ values are sensitive to the type of additives in Poly(vinyl chloride) films, which decrease in the following order: PVC $($ blank) $>(\theta)>(\varepsilon)>(r)>(r)>(I)$

PVC with additives

And this might point out to increase the photostability of this additives in this term.

\section{Acknowledgements}

The authors would like to thank Al-Nahrain University and Baghdad University for financial support and technical assistance on this work.

\section{References}

['] Yousif, E., Salimon, J., and Salih, N., Improvement of the Photostabilization of PVC Films in the Presence of thioacetic acid benzothiazole complexes. The malysian journal of analytical sciences, 10(1): ᄉ - 9Y, Y. 11.

$\left[{ }^{\Upsilon}\right]$ Yousif, E., Aliwi, M., Ameer, A., Ukal, J., Improved photostability of PVC films in the presence of $r$-thioacetic acid- ${ }^{-}$- phenyll, $\boldsymbol{r}, \Sigma$-oxadiazole complexes. Turk. J.

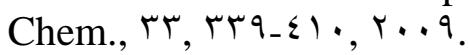

[r] Sabaa, M., Oraby, E., Abdel Naby, A., Mohamed, R., N-Phenyl-r-substituted- ${ }_{-}$pyrazolone derivatives as organic stabilizers for rigid Poly (vinyl chloride) against photodegradation. J. App. Polym. Sci., 1.', $10 \leqslant r-1000, r_{\ldots} . T$. 
[₹] Pimentel, Real 1., Ferraria, A., Botelho do Rego, A., Comparison of different photooxidation conditions of poly (vinyl chloride) for outdoor applications. Polymer Testing, $r \vee, \vee \leqslant r-v 01, r \cdots \wedge$.

[0] Andrady, A., Hamid, S., Hu, X. \& Torikai, A., Effects of increased solar ultraviolet radiation on materials. Journal of Photochemistry and photobiology, $\leq 7$ : 97 . 1.r, 1991.

[`] Gardette, J., Gaumet, S., Philippart, J., Influence of the experimental conditions on the photooxidation of poly (vinyl chloride). Journal of Applied Polymer Science. \&A(11): 1110_1190, 199\%.

[₹] Yousif, E., Salih, N., and Salimon, J., Improvement of the photostabilization of PVC films in the presence of $r \mathrm{~N}$ salicylidene- ${ }^{\circ}$-(substituted)- $,, r, \Sigma_{-}$

thiadiazole. Journal of Applied Polymer Science, $|r \cdot, r r \cdot V-r r| \leqslant, r \cdot 11$.

[^] Yousif, E., Ahmed, A., and Mahmoud, M. New organic photostabilizers for Rigid PVC against photodegradation. lambert academic pubilishing,Germany, $r \cdot 1 r$.

[9] Yousif, E. photostabilization of PVC: Principles and applications, lambert academic pubilishing, Germany, $r \cdot I r$.

[1•] Hussain, Z., Yousif, E., Ahmed, A., Altaie, A. Synthesis and characterization of Schiff's bases of sulphamethoxazole. Organic and medicinal letters, $\left.\leqslant: 1, r_{\cdot}\right) \leqslant$.

['] Khan R. S., Tawakkul M., Sayeed A. V., Faustino P., Khan A. M., Stability characterization, kinetics and mechanism of PH temperature, SciRes, $r, r \wedge)-r q \cdot, r \cdot 1 r$.

[IY] Yousif, E. Photostabilization of PVC: principle and applications. lambert, Germany, $r \cdot I^{\prime}$.

[1T] Gugumns, F., Development in polymer photostabilization- ', (G. Scott, ed.), Applied Science Publisher Ltd, London, Yr)-YVY, $19 \vee 9$.

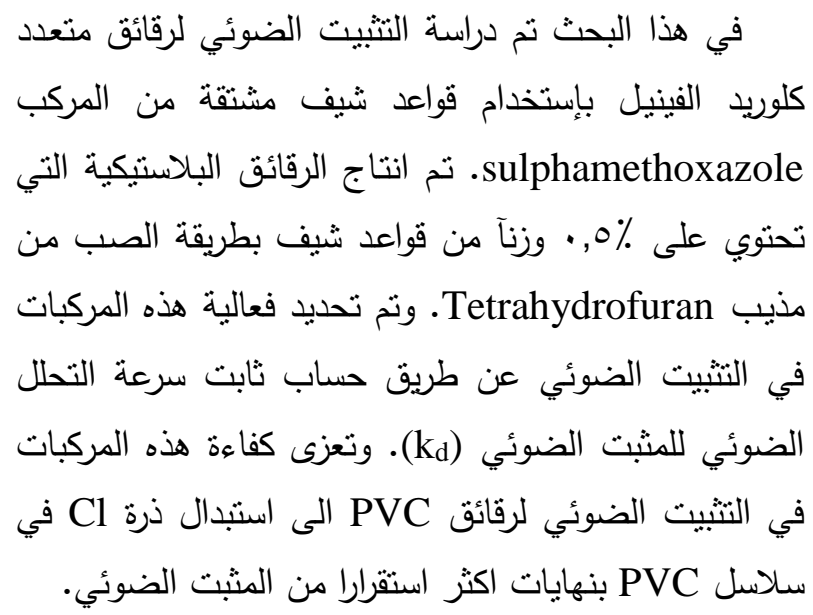

